\title{
Hypermethioninaemia due to methionine adenosyltransferase I/III (MAT I/III) deficiency: Diagnosis in an expanded neonatal screening programme
}

\author{
M. L. Couce • M. D. Bóveda • D. E. Castiñeiras • \\ F. J. Corrales • M. I. Mora • J. M. Fraga • S. H. Mudd
}

Received: 11 November 2007 /Submitted in revised form: 18 January 2008 / Accepted: 12 March 2008 / Published online: 20 May 2008

(C) SSIEM and Springer 2008

\begin{abstract}
Summary The Expanded Newborn Screening Program (MS/MS) in the region of Galicia (NW Spain) was initiated in 2000 and includes the measurement of methionine levels in dried blood spots. Between June 2000 and June 2007, 140818 newborns were analysed, and six cases of persistent hypermethioninaemia were
\end{abstract}

Communicating editor: Mohamed Rashed

Competing interests: None declared

References to electronic databases: MAT I/III deficiency (OMIM 250850)

M. L. Couce · M. D. Bóveda · D. E. Castiñeiras · J. M. Fraga

Unidad de Trastornos Metabólicos,

Departamento de Pediatría,

Hospital Clínico Universitario,

Santiago de Compostela, Spain

M. D. Bóveda $(\varangle)$

Laboratorio Metabolopatías,

Hospital Clínico Universitario,

Planta 0, Trav. Choupana s/n,

15706 Santiago de Compostela, Spain

e-mail: maria.boveda.fontan@sergas.es

F. J. Corrales • M. I. Mora

Centro de Investigación Médica Aplicada,

Universidad de Navarra,

Pamplona, Spain

S. H. Mudd

Laboratory of Molecular Biology,

National Institute of Mental Health,

Bethesda, MD, USA detected: one homocystinuria due to cystathionine $\beta$-synthase (CßS) deficiency, and five methionine adenosyltransferase I/III (MAT I/III) deficiencies. The five cases of MAT I/III deficiency represent an incidence of 1/28 163 newborns. In these five patients, methionine levels in dried blood spots ranged from 50 to $147 \mu \mathrm{mol} / \mathrm{L}$. At confirmation of the persistence of the hypermethioninaemia in a subsequent plasma sample, plasma methionine concentrations were moderately elevated in 4 of the 5 patients (mean $256 \mu \mathrm{mol} / \mathrm{L}$ ), while total homocysteine (tHcy) was normal; the remaining patient showed plasma methionine of $573 \mu \mathrm{mol} / \mathrm{L}$ and tHcy of $22.8 \mu \mathrm{mol} / \mathrm{L}$. All five patients were heterozygous for the same dominant mutation, $\mathrm{R} 264 \mathrm{H}$ in the MAT1A gene. With a diet not exceeding recommended protein requirements for their age, all patients maintained methionine levels below $300 \mu \mathrm{mol} / \mathrm{L}$. Currently, with a mean of 2.5 years since diagnosis, the patients are asymptomatic and show developmental quotients within the normal range. Our results show a rather high frequency of hypermethioninaemia due to MAT I/III deficiency in the Galician neonatal population, indicating a need for further studies to evaluate the impact of persistent isolated hypermethioninaemia in neonatal screening programmes.

\begin{tabular}{ll}
\multicolumn{2}{l}{ Abbreviations } \\
CBS & cystathionine $\beta$-synthase \\
MAT I/III & methionine adenosyltransferase I/III \\
MS/MS & tandem mass spectrometry \\
AdoMet & $\begin{array}{l}S \text {-adenosylmethionine } \\
\text { tHcy }\end{array}$ \\
total homocysteine
\end{tabular}




\section{Introduction}

Expanded neonatal screening programmes based on analysis of dried blood spots by tandem mass spectrometry (MS/MS) habitually include methionine measurement (Wilcken et al 2003). This permits diagnosis of classic homocystinuria (cystathionine $\beta$-synthase (CßS) deficiency) and hypermethioninaemia without homocystinuria. In addition to situations of transitory neonatal hypermethioninaemia, related to high methionine intake, and once type I tyrosinaemia and severe hepatic disease have been ruled out, isolated and persistent cases of hypermethioninaemia can be detected (Mudd et al 1995, 2001). With rare exceptions, this disorder is due to a methionine adenosyltransferase I/III (MAT I/III) deficiency.

MAT is the enzyme catalysing the synthesis of $S$-adenosylmethionine (AdoMet) from methionine and ATP. In mammals three forms of MAT have been described: MAT I, MAT II and MAT III. MAT II is encoded by the MAT2A gene, expressed mainly in extrahepatic tissues, fetal liver and hepatocarcinoma. MAT I and MAT III, expressed mainly in adult liver, are a tetramer and a dimer, respectively, of the same polypeptide chain, encoded by the MAT1A gene. MAT I/III deficiency (OMIM 250850) is caused by mutations in the $M A T 1 A$ gene that abolish or reduce the activity of this enzyme, leading to persistent hypermethioninaemia, as noted above. It can show either recessive or dominant autosomal inheritance (Blom et al 1992; Chamberlin et al 1997; Mudd et al 1995; Nagao and Oyanagi 1997). Most affected individuals do not present clinical symptoms, but some of those with the most severe losses of activity have developed neurological problems (tremor, dystonia, dysmetria, language difficulties or myelination disorders) and/or reduced intelligence or developmental quotients (Chamberlin et al 1996, 1997; Mudd et al 2000, 2001).

Cases of isolated persistent hypermethioninaemia have been diagnosed previously in neonatal screening programmes (Chien et al 2005; Kim et al 2002), but assessment of the impact of this abnormality in the population requires further studies. In our region, Galicia, the expanded neonatal screening programme using MS/MS was introduced in June 2000, and to date 140818 newborns have been analysed. A total of 6 cases of persistent hypermethioninaemia have been detected: one case of C $\beta S$ deficiency and 5 cases of MAT I/III deficiency (plus an additional case of MAT I/III deficiency, a sister, diagnosed subsequently). The patients with MAT I/III deficiency are all heterozygous for the same dominant mutation in the MAT1A gene. Here we report the diagnosis and follow-up of these cases.

\section{Patients and methods}

\section{Patients}

The five children ( 3 male, 2 female) who have now been diagnosed with MAT I/III deficiency were identified in their neonatal periods in Galicia over the last 7 years (between June 2000 and June 2007) in the Galician Program for Early Detection of Metabolic Alterations. The five children were all from Galician families, from different locations in the region. All have been monitored from diagnosis until the present in the Metabolic Disorders Unit of the University Clinical Hospital of Santiago de Compostela. All five showed methionine levels above the cut-off level in dried blood spots taken in the first few days of life (our newborn screening programme recommends the third day of life of the newborn). Quantitative analyses were also performed of amino acids and total homocysteine (tHcy) in plasma, and amino acids in urine. Once hypermethioninaemia without homocystinuria had been demonstrated (plasma tHcy normal or only slightly elevated), analysis of the MAT1A gene was performed.

Age, presence/absence of symptoms at diagnosis, and methionine levels at diagnosis and at confirmation were recorded for each case. Clinical course was subsequently monitored, recording mean and range of methionine level over time. The patients received a diet that did not exceed the recommended protein requirement for their age, permitting normal growth and development. Possible correlations between psychomotor development and methionine level were investigated at diagnosis and subsequently.

Methods

Neonatal screening by MS/MS analysis of dried blood spots in filter paper, obtained on the third day of life of the newborn

A blood paper disc was eluted with a solution of methanol containing internal standards of amino acids and acylcarnitines labelled isotopically with $\left[{ }^{2} \mathrm{H}_{3}\right]$ methionine (Cambridge Isotopes Laboratories, Inc., Andover, MA, USA). Derivatization to butyl esters was achieved by addition of a solution of hydrogen chloride in 1-butanol (Riedel-de Haën, ref. 35072). The residue was reconstituted with the mobile phase 
(acetonitrile-water 1:1, formic acid 0.05\%). An aliquot was injected into the mass spectrometer (Sciex API 2000). If the measured concentration exceeded the 99th centile for the study population, a second sample was requested. For methionine, this value ranged between 48 and $56 \mu \mathrm{mol} / \mathrm{L}$ over the study period.

\section{Quantitative analysis of amino acids in samples of plasma and urine}

This was carried out by ion-exchange chromatography (Biochrom 30 autoanalyser) after deproteinization of the sample (plasma or urine) with 5-sulfosalicylic acid, with post-column reaction with ninhydrin, and making use of L-norleucine as internal standard. The concentration of urinary amino acids is referred to creatinine concentration. Amino acid levels were evaluated with respect to reference ranges for the corresponding age group.

\section{Plasma tHcy}

Plasma tHcy was determined by HPLC with fluorometric detection using a Hitachi apparatus and a specific kit (Immundiagnostik AG, Bensheim, Germany). The tHcy level was considered to be elevated at concentrations above $15 \mu \mathrm{mol} / \mathrm{L}$.

\section{Molecular study}

DNA was isolated from $300 \mu$ l blood samples using the Puregene DNA isolation kit (Gentra Systems, Inc., Minneapolis, USA). The MAT1A gene was characterized by amplifying the coding regions of exons I to IX and the corresponding intron-exon junctions by PCR using nine pairs of oligonucleotide primers containing 5 -untranslated, 3 '-untranslated and intron sequences of the MAT1A gene as previously described (Ubagai et al 1995). All amplified fragments were sequenced using an ABI Prism DNA sequencing kit (Perkin Elmer, Waltham, MA, USA) and then processed on an ABI Prism 310 genetic analyser (Perkin Elmer). The sequences from all exons I to IX were examined to identify the presence of mutations.

\section{Anthropometric evaluation}

Body weight, body length and head circumference were measured and expressed as centiles with respect to the reference population.

\section{Evaluation of cognitive and psychomotor development}

The McCarthy Scales of Children's Abilities (MSCA) were used for preschool-age children, and the BrunetLézine scale for the child aged 13 months at evaluation. Cognitive and developmental quotients were considered normal from 85 .

\section{Results}

Since the extension of the Galician Neonatal Screening Program for Metabolic Abnormalities in June 2000 by the introduction of tandem mass spectrometry, 6 cases of persistent hypermethioninaemia have been detected (up to June 2007). Over this period, a total of 140818 newborns have been screened, indicating that persistent hypermethioninaemia has an incidence of 1 in 23470 in our region.

The six babies reported upon here were full-term and had normal birth weights, and their methionine elevations persisted. One of them was confirmed to have $\mathrm{C} \beta \mathrm{S}$ deficiency by enzymatic studies in fibroblasts and by genetic studies. The five remaining cases were confirmed by molecular studies of the MAT1A gene as MAT I/III deficiency, giving a frequency of one case in 28 163, similar to the results from Portugal reported

Table 1 Characteristics of the patients with MAT I/III deficiency

\begin{tabular}{|c|c|c|c|c|c|c|c|c|c|}
\hline \multirow[t]{2}{*}{ Patient } & \multirow[t]{2}{*}{ Current age } & \multirow[t]{2}{*}{ Sex } & \multicolumn{2}{|c|}{$\begin{array}{l}\text { Neonatal screening } \\
\text { (MS/MS) }\end{array}$} & \multicolumn{3}{|c|}{ Confirmation (plasma) } & \multirow[t]{2}{*}{ Mutation $M A T 1 A$} & \multirow[t]{2}{*}{ Nucleotide change } \\
\hline & & & Age & $\mathrm{Met}^{\mathrm{a}}$ & Age & $\mathrm{Met}^{\mathrm{a}}$ & $\mathrm{tHcy}^{\mathrm{a}}$ & & \\
\hline 1 & 2 y $10 \mathrm{~m}$ & $\mathrm{~F}$ & $6 \mathrm{~d}$ & 50 & $35 \mathrm{~d}$ & 573 & 22.8 & $\mathrm{R} 264 \mathrm{H}$ & $791 \mathrm{~g} / \mathrm{a}$ \\
\hline 2 & 2 y $8 \mathrm{~m}$ & M & $3 \mathrm{~d}$ & 100 & $1 \mathrm{~m} 15 \mathrm{~d}$ & 189 & 8.9 & $\mathrm{R} 264 \mathrm{H}$ & $791 \mathrm{~g} / \mathrm{a}$ \\
\hline 3 & 2 y $7 \mathrm{~m}$ & $\mathrm{~F}$ & $5 \mathrm{~d}$ & 88 & $2 \mathrm{~m} 21 \mathrm{~d}$ & 341 & 9.7 & $\mathrm{R} 264 \mathrm{H}$ & $791 \mathrm{~g} / \mathrm{a}$ \\
\hline 4 & 2 y $6 \mathrm{~m}$ & M & $3 \mathrm{~d}$ & 147 & $2 \mathrm{~m} 13 \mathrm{~d}$ & 331 & 12.4 & $\mathrm{R} 264 \mathrm{H}$ & $791 \mathrm{~g} / \mathrm{a}$ \\
\hline 5 & $1 \mathrm{y} 4 \mathrm{~m}$ & M & $5 \mathrm{~d}$ & 100 & $25 \mathrm{~d}$ & 164 & 11.0 & $\mathrm{R} 264 \mathrm{H}$ & $791 \mathrm{~g} / \mathrm{a}$ \\
\hline
\end{tabular}

$\mathrm{y}$, year; m, month; d, day.

${ }^{\mathrm{a}} \mu \mathrm{mol} / \mathrm{L}$. 
recently (Martins et al 2007), but a higher incidence than that reported for other areas, such as Taiwan (Chien et al 2005; Hwu 2004). However, for almost all the infants reported from Taiwan the cut-off point for methionine was $134 \mu \mathrm{mol} / \mathrm{L}$, considerably higher than the cut-off range, $48-56 \mu \mathrm{mol} / \mathrm{L}$, used in our present programme.

All five of our cases were heterozygous for the same mutation in MAT1A, R264H $(\mathrm{G}>\mathrm{A}$ at nucleotide 791). This mutation shows a dominant phenotype, since the mutated subunit sequesters normal subunits to form inactive dimers (Chamberlin et al 1997; PerezMato et al 2001). Table 1 shows methionine levels in neonatal screening samples taken within 3-6 days of birth (the programme recommends sampling on day 3 of life). All patients initially presented with only moderately elevated values (mean $97 \mu \mathrm{mol} / \mathrm{L}$, range 50-147). Persistence of the isolated hypermethioninaemia was confirmed in subsequent plasma samples in which the methionine levels were higher than at detection but still only moderately elevated in 4 of the 5 cases (patients 2, 3, 4 and 5) (mean $256 \mu \mathrm{mol} / \mathrm{L}$, range 164-341), with tHcy values within the normal range (mean $10.5 \mu \mathrm{mol} / \mathrm{L}$, range $8.9-12.4 \mu \mathrm{mol} / \mathrm{L}$ ). Only patient 1 showed more markedly elevated plasma methionine $(573 \mu \mathrm{mol} / \mathrm{L})$, together with slightly elevated tHcy $(22.8 \mu \mathrm{mol} / \mathrm{L})$. Interestingly, this was the case with the lowest level of methionine at initial diagnosis $(50 \mu \mathrm{mol} / \mathrm{L}$ at 6 days of age). This was also the first patient with persistent hypermethioninaemia detected in our region's neonatal screening programme. However, mild elevations of plasma tHcy are known to occur in MAT I/III deficiency (Ito et al 2003; Linnebank et al 2005; Stabler et al 2002). Furthermore, in patient 1 the plasma values of AdoMet and $S$-adenosylhomocysteine were not elevated (128 and $32 \mu \mathrm{mol} / \mathrm{L}$, respectively), and cystathionine was somewhat above the reference range (575 $\mathrm{nmol} / \mathrm{L}$ ). These findings were supportive of MAT I/III deficiency and against CBS deficiency. In the 4 patients detected subsequently, these components were not determined, but sequencing of their MAT1A genes showed $\mathrm{R} 264 \mathrm{H}$ mutations, indicating the presence of MAT I/III deficiency and providing an explanation for their hypermethioninaemia (Andria et al 2005; Mudd et al 2003).

Plasma methionine was assayed in both parents of five of the patients. In each family one of the parents had an elevated concentration (Table 2), as expected in view of the Mendelian dominance of $\mathrm{R} 264 \mathrm{H}$. The father of patient 2 did not consent to an assay. In addition, a new case of MAT I/III deficiency was detected in a sister of patient 1 , currently aged 7 years (plasma methionine $124 \mu \mathrm{mol} / \mathrm{L}$ ). This girl, who likewise showed the R264H mutation, was born before the expanded screening programme commenced. Four of the parents who show hypermethioninaemia are clinically well. The father of patient 4 has a cardiopathy not related to his hypermethioninaemia, and shows moderately elevated levels of (hepatic) transaminases, attributed to the pharmacological treatment he receives.

All patients were prescribed free diets appropriate for their ages without an excess of proteins but an intake within the normal limits (FAO/WHO). Physical development was normal in all patients, and none showed clinical symptoms. Table 2 summarizes followup of the patients studied, from confirmation of diagnosis until the present, showing mean methionine levels, number of determinations in each patient, and minimum and maximum values recorded for each patient. As can be seen, mean methionine levels were in all cases below $300 \mu \mathrm{mol} / \mathrm{L}$. Developmental quotients (DQs) were not significantly correlated with methionine levels at diagnosis and these quotients remained within the normal range in all cases, though

Table 2 Follow-up and family study of the 5 cases

\begin{tabular}{|c|c|c|c|c|c|c|}
\hline \multirow[t]{2}{*}{ Patient } & \multicolumn{2}{|c|}{ Plasma methionine $^{\mathrm{a}}$} & \multirow[t]{2}{*}{ DQ } & & \multicolumn{2}{|c|}{ Family study (plasma $\mathrm{Met}^{\mathrm{a}}$ ) } \\
\hline & Mean (min-max) & $\mathrm{n}^{\mathrm{b}}$ & & & Father & Mother \\
\hline 1 & $163.8(43-585)$ & 11 & 100 & 2 y $8 \mathrm{~m}$ & 74 & $27(\mathrm{~N})$ \\
\hline 2 & $152.1(84-247)$ & 10 & 103 & 2 y $6 \mathrm{~m}$ & n.a. & $23(\mathrm{~N})$ \\
\hline 3 & $237.0(149-364)$ & 8 & 88 & 2 y $6 \mathrm{~m}$ & $24(\mathrm{~N})$ & 76 \\
\hline 4 & $183.4(58-330)$ & 8 & 101 & 2 y $6 \mathrm{~m}$ & 205 & $19(\mathrm{~N})$ \\
\hline 5 & $117.2(49-173)$ & 5 & 101 & $13 \mathrm{~m}$ & $25(\mathrm{~N})$ & 85 \\
\hline
\end{tabular}

y, year; m, month; (N) normal range; n.a., not assayed.

${ }^{\mathrm{a}} \mu \mathrm{mol} / \mathrm{L}$.

${ }^{\mathrm{b}}$ Number of determinations. 
patient 3 (with the highest mean methionine level at regular monitoring) showed the lowest DQ $(88$, at the lower limit of the normal range).

\section{Discussion}

Neonatal screening for hypermethioninaemia is not easy, for diverse reasons. On the one hand, methionine levels in blood are not always high enough for detection of C $\beta S$ deficiency during the first days of life and, on the other hand, differential diagnosis may be complicated, leading to a high number of requests for repeat sampling in view of elevated methionine, with consequent high economic and social costs in a population-level screening programme. However, once transient hypermethioninaemias due to use of milk with high methionine content have been ruled out (above all in premature newborns and other newborns with low body weight (see ten Hoedt et al 2007)), it is important to note that detection of cases of MAT I/III deficiency can be achieved only by monitoring of hypermethioninaemia, however moderate this may be; patient 1 in the present study is a clear example of this situation because she showed a blood methionine level in the first sample of $50 \mu \mathrm{mol} / \mathrm{L}$, very near to the cut-off (Table 1).

Advances in knowledge of mutations in the MAT1A gene have allowed non-aggressive diagnosis of both the presence of MAT I/III deficiency and the extent of the deficit in enzyme activity, removing any need for hepatic biopsy (Chamberlin et al 1997, 2000; Kim et al 2002). The gradual worldwide spread of expanded neonatal screening programmes (using MS/MS) will lead to the detection of an increasing number of cases of isolated persistent hypermethioninaemias due to deficient MAT I/III activity. In the population considered in the present study, for example, diagnosis of the sister of patient 1 was late, because methionine level had not been determined in the neonatal period.

The most suitable management of individuals with MAT I/III mutations has not been definitively established, in part because relatively few patients are known; in part because, having usually been detected by newborn screening, these patients are still young; and in part because the optimal treatment will probably vary with the type of causative MAT1A mutation(s). To date, among the very few individuals known to have complete loss of MAT I/III activity some have developed adverse clinical manifestations (mental retardation; neurological disorders, especially myelination defects; and body odour). The observed neurotoxicity may perhaps be attributable to deficient formation of AdoMet and, in a single reported case, treatment with AdoMet was accompanied by reversal of demyelination (Surtees et al 1991). In addition, high levels of methionine $(>1000 \mu \mathrm{mol} / \mathrm{L})$ may inhibit transport of other neutral amino acids into the brain, with neurotoxic effects (Mudd et al 1995). However, other individuals with no MAT I/III activity have remained clinically normal (Hazelwood et al 1998; Mudd et al 2001). Synthesis of AdoMet by MAT II, encoded by a different gene, may sustain these individuals. The known individuals with point mutations in MAT1A and some residual, albeit far below normal, MAT I/III activity have so far been clinically normal. With respect to heterozygosity for the MAT1A R264H mutation, it is encouraging that the parents of our patients, including the father of patient 4 with a particularly high plasma methionine level (205 $\mu \mathrm{mol} / \mathrm{L}$ ), as well as other reported individuals with raised plasma methionine due to such heterozygosity have all been free of clinical difficulties attributable to this mutation, even those who are elderly (Mudd et al 2001). Although there was clearly overlap in the ranges, the plasma methionine values found in the parents tended to be lower than those in their affected children (Table 2). Similar tendencies are apparent in the other families for which generational values have been reported (Chamberlin et al 1997; Nagao and Oyanagi 1997). The reasons for such a trend are not established, but it may be dependent upon developmental changes with ageing: plasma methionines tended, on the whole, to decrease in the two R264 heterozygous children (Chamberlin et al 1997) for whom age-dependent values were reported by Blom and co-workers (Blom et al 1992); and Nagao and coworkers found in three heterozygous children a mean plasma methionine of $354 \mu \mathrm{mol} / \mathrm{L}$ (range 295-391 $\mu \mathrm{mol} / \mathrm{L}$ ) at age 0.1 years that had decreased to a mean of $226 \mu \mathrm{mol} / \mathrm{L}$ (range $128-385 \mu \mathrm{mol} / \mathrm{L}$ ) at ages $10-12$ years. For the heterozygous parents of these children the mean was $181 \mu \mathrm{mol} / \mathrm{L}$ (range $155-201 \mu \mathrm{mol} / \mathrm{L}$ ) at ages $26-28$ years and $134 \mu \mathrm{mol} / \mathrm{L}$ (range $111-148 \mu \mathrm{mol} / \mathrm{L}$ ) at ages 37-40 years (Nagao and Oyanagi 1997).

None of our patients showed neurological symptoms, and thus none of them received treatment. Some authors (Chien et al 2005) have limited dietary methionine intake for patients with persistent isolated hypermethioninaemia, maintaining plasma levels below $150 \mu \mathrm{mol} / \mathrm{L}$. However, there is concern that such limitation may be counterproductive if it further reduces synthesis of AdoMet in those with some residual MAT I/III activity. At methionine levels above $300 \mu \mathrm{mol} / \mathrm{L}$, metabolites produced by transamination may give rise to the offensive body odour seen 
in some patients, although there is no clear evidence that this is otherwise harmful (Andria et al 2005; Gahl et al 1988; Mudd et al 1995). We therefore consider that strict limitation of dietary methionine intake is unnecessary and indeed inadvisable. In our patient 1 , in view of the plasma methionine above $500 \mu \mathrm{mol} / \mathrm{L}$ and the slightly elevated tHcy, we initially considered use of a methionine-restricted diet. However, methionine levels dropped to a mean of $164 \mu \mathrm{mol} / \mathrm{L}$ on a normal diet, the presence of the $\mathrm{R} 264 \mathrm{H}$ mutation was established, and dietary treatment was not carried out. The correlation between DQ and methionine levels observed in patient 3 does not appear to be important, but will be monitored in future follow-ups.

With respect to management of MAT I/III deficiency, one note of caution may be mentioned: Recently, a patient with a plasma methionine of $740 \mu \mathrm{mol} / \mathrm{L}$ and a tHcy of $37 \mu \mathrm{mol} / \mathrm{L}$ was described who was suspected of having $\mathrm{C} \beta \mathrm{S}$ deficiency. During treatment that included betaine administration, the methionine rose to 960 $1560 \mu \mathrm{mol} / \mathrm{L}$ and the patient developed brain oedema. When it was realized that the correct diagnosis was MAT I/III deficiency, the betaine was discontinued and the brain oedema largely resolved (Tada et al 2004). There is evidence that extreme elevations of methionine due to a variety of causes (perhaps especially when accompanied by betaine administration) may lead to severe brain oedema (Braverman et al 2005). This possibility should be borne in mind when dealing with MAT I/III deficiency.

\section{Conclusions}

The incidence of MAT I/III deficiency in our population is higher than has been reported in some previous studies. It is worth noting that all of our patients showed the same dominant mutation in MAT1A, despite the fact that, to date, 27 mutations of this gene have been published. Biochemical and clinical monitoring of these patients is important in case they need $S$-adenosylmethionine supplementation, or, far less likely, dietary restriction of methionine intake.

Acknowledgements The authors thank Dr Conrad Wagner for assays of plasma AdoMet and $S$-adenosylhomocysteine, and Dr Sally Stabler for assay of plasma cystathionine.

\section{References}

Andria G, Fowler B, Sebastio G (2005) Disorders of sulfur amino acid metabolism. In: Fernández J, Saudubray JM, Van den Berghe G, Walter JH, eds. Inborn Metabolic Diseases, 4th edn. Würzburg: Springer Medizin Verlag, 273-282.
Blom HJ, Davidson AJ, Finkelstein JD, et al (1992) Persistent hypermethioninemia with dominant inheritance. $J$ Inherit Metab Dis 15: 188-197.

Braverman NE, Mudd SH, Barker PB, Pomper MG (2005) Characteristic MR imaging changes in severe hypermethioninemic states. Am J Neuroradiol 26: 2705-2706.

Chamberlin ME, Ubagai T, Mudd SH, Wilson WG, Leonard JV, Chou JY (1996) Demyelination of the brain is associated with methionine adenosyltransferase I/III deficiency. J Clin Invest 98: 1021-1027.

Chamberlin ME, Ubagai T, Mudd SH, Levy HL, Chou JY (1997) Dominant inheritance of isolated hypermethioninaemia is associated with a mutation in the human methionine adenosyltransferase 1A gene. Am J Hum Genet 60: 540-546.

Chamberlin ME, Ubagai T, Mudd SH, et al (2000) Methionine adenosyltransferase I/III deficiency: novel mutations and clinical variations. Am J Hum Genet 66: 347-355.

Chien Y, Chiang S, Huang A, Hwu W (2005) Spectrum of hypermethioninemia in neonatal screening. Early Hum Dev 81: $529-533$.

Gahl WA, Bernardini I, Finkelstein JD, et al (1988) Transsulfuration in an adult with hepatic methionine adenosyltransferase deficiency. J Clin Invest 81: 390-397.

Hazelwood S, Bernardini I, Tangerman A, et al (1998) Lack of brain demyelination in a patient homozygous for a mutation encoding a severely truncated methionine adenosyltransferase I/III. Am J Med Genet 75: 395-400.

Hwu WL (2004) Neonatal screening in Taiwan. The 5th Asia Pacific Regional Meeting of the International Society for Neonatal Screening; Shanghai, China.

Ito M, Kotani Y, Matsuda J, et al (2003) A methionine adenosyltransferase (MAT) deficiency patient treated with diet therapy. J Inherit Metab Dis 26(Supplement 2): 76.

Kim SZ, Santamaria E, Jeong TE, et al (2002) Methionine adenosyltransferase I/III deficiency: two Korean compound heterozygous siblings with a novel mutation. J Inherit Metab Dis 25: 661-671.

Linnebank M, Lagler F, Muntau AC, et al (2005) Methionine adenosyltransferase (MAT) I/III deficiency with concurrent hypermethioninemia and hyperhomocysteinemia: two novel cases. J Inherit Metab Dis 28: 1167-1168.

Martins E, Eusebio F, Marcao A, Rocha H, Vilarinho L (2007) Five families with hypermethioninemia associated with the dominantly inherited methionine adenosyltransferase I/III form deficiency. J Inherit Metab Dis 30(Supplement 1): 6.

Mudd SH, Levy HL, Tangerman A, et al (1995) Isolated persistent hypermethioninemia. Am J Hum Genet 57: 882-892.

Mudd SH, Jenden DJ, Capdevila A, Roch M, Levy HL, Wagner C (2000) Isolated hypermethioninemia: measurements of S-adenosylmethionine and choline. Metabolism 49: 1542-1547.

Mudd SH, Levy HL, Kraus JP (2001) Disorders of transsulfuration. In: Scriver CR, Beaudet AL, Sly WS, Valle D, eds; Childs B, Kinzler KW, Vogelstein B, assoc, eds. The Metabolic and Molecular Bases of Inherited Disease, 8th edn. New York: McGraw-Hill, 2007-2056.

Mudd SH, Braverman N, Pomper M, et al (2003) Infantile hypermethioninemia and hyperhomocysteinemia due to high methionine intake: a diagnosis trap. Mol Genet Metab 79: 6-16.

Nagao M, Oyanagi K (1997) Genetic analysis of isolated persistent hypermethioninemia with dominant inheritance. Acta Paediatr Jpn, 39: 601-606.

Perez-Mato I, Sanchez del Pino M, Chamberlin M, Mudd SH, Mato JM, Corrales FJ (2001) Biochemical basis for the dominant inheritance of hypermethioninemia associated with the R264H mutation of the MAT1A gene. $J$ Biol Chem 276: 13803-13809. 
Stabler SP, Steegborn C, Wahl MC, et al (2002) Elevated plasma total homocysteine in severe MAT I/III deficiency. Metabolism 51: 981-988.

Surtees R, Leonard J, Austin S (1991) Association of demyelination with deficiency of cerebrospinal-fluid $S$-adenosylmethionine in inborn errors of methyl-transfer pathway. Lancet 338: $1550-1554$.

Tada H, Takanashi JI, Barkovitch AJ, Yamamoto S, Kohno Y (2004) Reversible white matter lesion in methionine adenosyltransferase I/III deficiency. Am J Neuroradiol 25: 1843-1845. ten Hoedt AE, van Kempen AA, Boelen A, et al (2007) High incidence of hypermethioninaemia in a single neonatal intensive care unit detected by a newly introduced neonatal screening programme. J Inherit Metab Dis 30: 978.

Ubagai T, Lei KJ, Huang S, Mudd SH, Levy HL, Chou JY (1995) Molecular mechanisms of an inborn error of methionine pathway. J Clin Invest 96: 1943-1947.

Wilcken B, Wiley V, Hammond J, Carpenter K (2003) Screening newborns for inborn errors of metabolism by tandem mass spectrometry. N Engl J Med 348: 2305-2312. 